From the Free University Medical Center, Amsterdam, the Netherlands; Thoraxklinik, Heidelberg; Asklepios Fachkliniken, Munich-Gauting; Krankenhaus Grosshansdorf, Grosshansdorf, Germany; S. Luigi Gonzaga Hospital, Turin, Italy; Hospital Germans Trias i Pujol, Barcelona, Spain; Regional Center of Oncology, Lodz, Poland; AstraZeneca, Alderley Park, United Kingdom; University of Texas M.D. Anderson Cancer Center, Houston, TX; Memorial SloanKettering Cancer Center, New York, NY; Cedars-Sinai Comprehensive Cancer Center, Beverly Hills, CA; the University of Wisconsin Hospital and Clinics, Madison, Wl: AstraZeneca

Pharmaceuticals, Wilmington, DE; and Vanderbilt-Ingram Cancer Center, Nashville, TN

Submitted August 1, 2003; accepted December 2, 2003.

Supported by a grant from AstraZeneca, Wilmington, DE.

Authors' disclosures of potential conflicts of interest are found at the end of this article.

Address reprint requests to Giuseppe Giaccone, MD, Vrije Universiteit Medical Center, Department of Oncology, De Boelelaan 1117, 1081 Amsterdam, the Netherlands; e-mail: g.giaccone@ vumc.nl.

C 2004 by American Society of Clinical Oncology

0732-183X/04/2205-777/\$20.00

DOI: $10.1200 / J C O .2004 .08 .001$

\title{
Gefitinib in Combination With Gemcitabine and Cisplatin in Advanced Non-Small-Cell Lung Cancer: A Phase III Trial-INTACT 1
}

Giuseppe Giaccone, Roy S. Herbst, Christian Manegold, Giorgio Scagliotti, Rafael Rosell, Vincent Miller, Ronald B. Natale, Joan H. Schiller, Joachim von Pawel, Anna Pluzanska, Ulrich Gatzemeier, John Grous, Judith S. Ochs, Steven D. Averbuch, Michael K. Wolf, Pamela Rennie, Abderrahim Fandi, and David H. Johnson

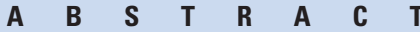

\section{Purpose}

The purpose of this study was to determine whether the addition of the epidermal growth factor receptor tyrosine kinase inhibitor gefitinib (Iressa, ZD1839; AstraZeneca, Wilmington, DE) to standard first-line gemcitabine and cisplatin provides clinical benefit over gemcitabine and cisplatin alone in patients with advanced or metastatic non-small-cell lung cancer (NSCLC). Gefitinib has demonstrated encouraging efficacy in advanced NSCLC in phase II trials in pretreated patients, and a phase I trial of gefitinib in combination with gemcitabine and cisplatin showed favorable tolerability.

\section{Patients and Methods}

This was a phase III randomized, double-blind, placebo-controlled, multicenter trial in chemotherapynaive patients with unresectable stage III or IV NSCLC. All patients received up to six cycles of chemotherapy (cisplatin $80 \mathrm{mg} / \mathrm{m}^{2}$ on day 1 and gemcitabine $1,250 \mathrm{mg} / \mathrm{m}^{2}$ on days 1 and 8 of the 3-week cycle) plus either gefitinib $500 \mathrm{mg} / \mathrm{d}$, gefitinib $250 \mathrm{mg} / \mathrm{d}$, or placebo. Daily gefitinib or placebo was continued until disease progression. End points included overall survival (primary), time to progression, response rates, and safety evaluation.

\section{Results}

A total of 1,093 patients were enrolled. There was no difference in efficacy end points between the treatment groups: for the gefitinib $500 \mathrm{mg} / \mathrm{d}$, gefitinib $250 \mathrm{mg} / \mathrm{d}$, and placebo groups, respectively, median survival times were 9.9, 9.9, and 10.9 months (global ordered log-rank [GOLrank] $P=.4560$ ), median times to progression were 5.5, 5.8, and 6.0 months (GOLrank; $P=.7633$ ), and response rates were $49.7 \%, 50.3 \%$, and $44.8 \%$. No significant unexpected adverse events were seen.

\section{Conclusion}

Gefitinib in combination with gemcitabine and cisplatin in chemotherapy-naive patients with advanced NSCLC did not have improved efficacy over gemcitabine and cisplatin alone. The reasons for this remain obscure and require further preclinical testing.

J Clin Oncol 22:777-784. (C) 2004 by American Society of Clinical Oncology

\section{INTRODUCTION}

Platinum-based combination chemotherapy constitutes standard treatment for patients with advanced or metastatic nonsmall-cell lung cancer (NSCLC) and a good performance status. Chemotherapy has demonstrated modest but significant improvements in survival rates over best supportive care [1]. However, the prognosis for patients receiving platinum-based chemotherapy as first-line treatment for advanced NSCLC remains poor and side effects are considerable [2]; therefore, novel agents are urgently needed for this disease. One of the most widely used platinum-based combinations is gemcitabine and cisplatin. In two phase III studies of chemotherapy-naive patients with advanced NSCLC, the response rates for patients receiving gemcitabine and cisplatin were $30.4 \%$ to $40.6 \%$, median times to 


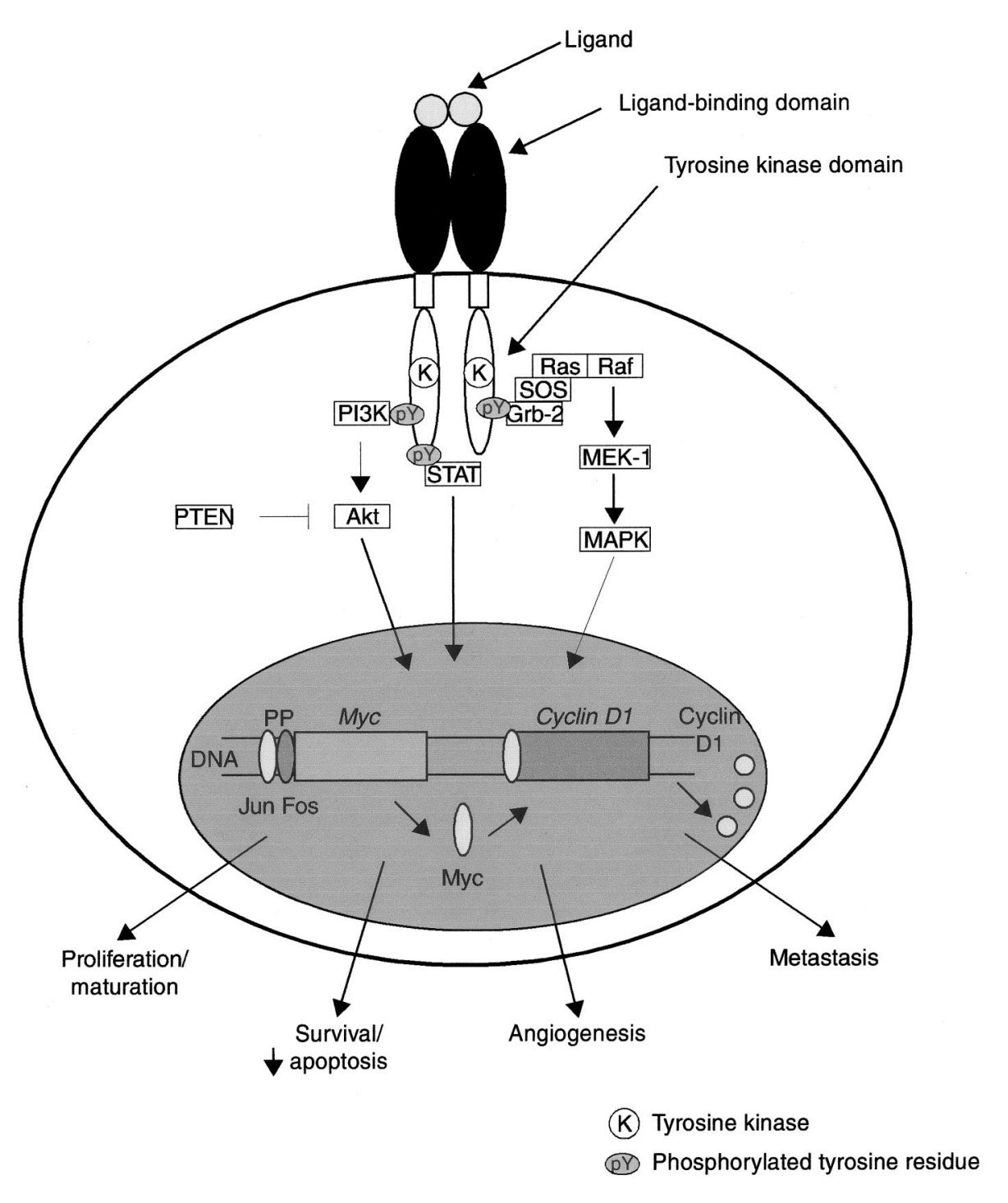

Fig 1. Epidermal growth factor receptor signal transduction. Adapted with permission [5].

progression were 5.6 to 6.9 months, and overall survival times were 8.7 to 9.1 months $[3,4]$.

The epidermal growth factor receptor (EGFR) has been shown to play an important role in the growth and survival of many solid tumors, including NSCLC. Activation of EGFR enhances the processes responsible for tumor growth and progression, including the promotion of proliferation, angiogenesis, and invasion/metastasis and inhibition of apoptosis (Fig 1) [5-7]. Gefitinib (Iressa, ZD1839; AstraZeneca, Wilmington, DE) is an orally active EGFR tyrosine kinase inhibitor (EGFR-TKI) that blocks the signal transduction pathways implicated in the proliferation and survival of cancer cells [7].

Two phase II trials of gefitinib monotherapy in patients with pretreated advanced NSCLC demonstrated encouraging antitumor activity (objective response rates, $11.8 \%$ to
$18.4 \%$ ) and symptom relief (symptom improvement rates, $40.3 \%$ to $43.1 \%$ ) and good tolerability [8-11]. This favorable tolerability profile, coupled with its mechanism of action, which is distinct from that of cytotoxic agents, provides a strong rationale for use of gefitinib in combination with standard cytotoxic regimens. This rationale is supported by data from preclinical studies in which gefitinib potentiated the efficacy of various cytotoxic drugs against a range of human solid tumor types, both in vitro and in vivo $[12,13]$. In particular, synergy was observed when gefitinib and cisplatin were used in combination, whereas no synergy could be demonstrated between gemcitabine and gefitinib [13].

On the basis of phase I trials of gefitinib monotherapy, two doses were identified for further study based on pharmacokinetics and clinical activity. Gefitinib $250 \mathrm{mg} / \mathrm{d}$ is higher than the lowest dose at which clinical responses were 
seen $(150 \mathrm{mg} / \mathrm{d})$, and $500 \mathrm{mg} / \mathrm{d}$ is the highest dose level that is well tolerated for a long period by most patients. A feasibility study of daily oral gefitinib (250 and $500 \mathrm{mg} / \mathrm{d}$ ) in combination with gemcitabine and cisplatin demonstrated a manageable and predictable tolerability profile with no evidence of any clinically significant pharmacokinetic interactions between gefitinib and cisplatin or gemcitabine [14]. Encouraging antitumor activity was seen in a range of solid tumors at both gefitinib doses in this study [14].

Here we present the results from a multinational, randomized, double-blind, placebo-controlled phase III study. The Iressa NSCLC Trial Assessing Combination Treatment (INTACT) 1 investigated the efficacy and safety of gefitinib (250 and $500 \mathrm{mg}$ once daily) versus placebo in combination with cisplatin plus gemcitabine in chemotherapy-naive patients with advanced NSCLC. The primary objective was to assess whether gefitinib increases overall survival relative to placebo in combination with cisplatin and gemcitabine. A second trial of identical design (INTACT 2) has been conducted to investigate gefitinib in combination with paclitaxel plus carboplatin, another commonly used combination in patients with advanced NSCLC [15].

\section{PATIENTS AND METHODS}

Patients were randomly assigned to one of three treatment groups in a double-blind manner. All patients received gemcitabine and cisplatin in combination with gefitinib $500 \mathrm{mg} / \mathrm{d}$, gefitinib 250 $\mathrm{mg} / \mathrm{d}$, or placebo. Patients were further stratified by dynamic randomization [16] according to weight loss in previous 6 months $(\leq 5 \% v>5 \%)$, disease stage (III $v$ IV), performance status ( 0 to $1 \vee 2$ ), and measurable disease (yes $v$ no).

\section{Treatment}

Gefitinib or placebo was administered orally, once daily. Chemotherapy was administered in 3-week cycles for a total of six cycles: intravenous gemcitabine $1,250 \mathrm{mg} / \mathrm{m}^{2}$ for 30 minutes on days 1 and 8 ; intravenous cisplatin $80 \mathrm{mg} / \mathrm{m}^{2}$ after gemcitabine administration on day 1 only. Subsequently, patients continued on gefitinib or placebo until disease progression. One gefitinib/ placebo dose reduction (500 to $250 \mathrm{mg} / \mathrm{d}$ or 250 to $100 \mathrm{mg} / \mathrm{d}$ ) was allowed per patient. In the event of grade 3 or 4 adverse events not thought to be due to disease progression or gemcitabine and cisplatin, gefitinib administration could be interrupted for a maximum of 14 days.

\section{Eligibility Criteria}

The inclusion criteria included histologically/cytologically confirmed NSCLC, locally advanced stage III disease not curable with surgery or radiotherapy or stage IV disease, aged $\geq 18$ years, and WHO performance status of 0 to 2 . Patients were not eligible for this trial if they had previously received chemotherapy (prior surgery or localized radiation were allowed); were hypersensitive to mannitol, corticosteroids, $\mathrm{H}_{2}$-antagonists, antihistamines or agents formulated with polyoxyethylated castor oil; had received radiotherapy within the last 2 weeks; had unresolved toxicity from previous radiation therapy or incomplete healing from previous surgery; had preexisting motor or sensory neurotoxicity (National Cancer Institute Common Toxicity Criteria $\geq$ grade 2); showed evidence of severe or uncontrolled systemic disease; had recent conditions requiring medication or uncontrolled significant active infections; had an absolute neutrophil count less than $2,000 / \mathrm{mm}^{3}$, WBCs less than $4,000 / \mathrm{mm}^{3}$, or platelets less than $100,000 / \mathrm{mm}^{3}$; had serum bilirubin greater than 1.25 times the upper limit of reference range (ULRR), ALT or AST greater than 2.5 times ULRR (five times ULRR in the presence of liver metastases), serum creatinine greater than 1.5 times ULRR, or creatinine clearance less than $60 \mathrm{~mL} / \mathrm{min}$; were pregnant or breast-feeding; had other coexisting malignancies or malignancies diagnosed within the last 5 years with the exception of basal-cell carcinoma or cervical cancer in situ; or had mixed NSCLC plus small-cell lung cancer. Patients with stable brain metastasis or spinal-cord compression were eligible. All patients signed a written informed consent form, and trial approval was obtained from the ethics committee at each trial center. The study followed the Declaration of Helsinki [17] and good clinical practice guidelines.

\section{Assessments}

Overall survival and time to progression were assessed from the date of randomization to the date of patient death and the date of objective disease progression (death was considered a progression event in those patients who died before disease progression), respectively. Patients without documented death or objective progression at the time of the final analysis were censored at the date they were last known to be alive or of their last objective tumor assessment, respectively. Tumor response was evaluated according to Response Evaluation Criteria in Solid Tumors [18]. During the trial and for 30 days after the last dose of gefitinib or placebo, patients were monitored for adverse events, which were graded according to the National Cancer Institute Common Toxicity Criteria. Hematology and biochemistry assessments were performed $\leq 7$ days before the date of randomization and at each clinic visit.

\section{Statistical Analysis}

An Independent Data Monitoring Committee provided ongoing guidance and recommendations for patient management, based on review of the formal interim efficacy analysis, and also reviewed safety data on an ad-hoc basis, as determined by a steering committee. The role of the committee was to provide executive oversight and supervision for the conduct of the trial, through review of trial enrollment, protocol and clinical conduct, and blinded safety data.

Gefitinib was compared with placebo on an intent-to-treat basis with respect to overall survival. The study was designed to have $90 \%$ power for a two-sided overall significance level test of the hypothesis that gefitinib increases survival relative to placebo given a hazard ratio of 1.33 . Assuming a 1-year survival rate of $30 \%$ in the placebo arm, this hazard ratio equates to an increase in median survival of 2.3 months for both gefitinib arms. The final analysis of overall survival was planned to include 750 events. On the basis of the study design assumptions, 1,029 patients were required.

An adaptive survival analysis procedure was used at the final analysis that tested either for a positive or negative gefitinib doseresponse relationship based on prospective criteria applied to the observed data. A survival trend test (global ordered log-rank test [GOLrank]) was to be used for a positive dose-response relationship, whereas pairwise log-rank tests would be used for a mixed dose-response relationship [19]. To preserve an overall two-sided $5 \%$ significance level, and to account for the use of a GOLrank test 
at an interim analysis, simulations with the adaptive procedure were used to calculate a nominal significance level of $4.4 \%$ for the final analysis. According to prospective criteria for the adaptive procedure, the final analysis used a GOLrank test to compare survival between the treatment arms.

A posthoc multivariate analysis with eight prespecified prognostic factors at trial entry (disease stage III $v$ IV; performance status 0 or $1 v 2$; weight loss in prior 6 months $\leq 5 \% v>5 \%$; sex; histology; presence or absence of metastases to bone, liver, or brain) was performed to assess which variables predicted improved survival.

In a posthoc subgroup analysis, stratification and prognostic factors (disease stage III $v$ IV; performance status 0 or $1 v 2$; weight loss in prior 6 months $\leq 5 \% v>5 \%$; presence or absence of metastases to bone, liver, or brain) and subgroups of sex and histology were examined in a univariate model. An unadjusted Cox proportional hazard test was applied to the overall survival data for each subgroup to estimate the hazard ratio and 95\% CI for the treatment comparisons of gefitinib 250 or $500 \mathrm{mg} / \mathrm{d}$ versus placebo.

\section{RESULTS}

\section{Patients}

In total, 1,093 patients were enrolled from 155 centers between May 2000 and March 2001. Most patients were enrolled by European trial centers $(\mathrm{n}=816 ; 74.7 \%)$, but patients were also enrolled in North America $(\mathrm{n}=139$; $12.7 \%)$, Asia ( $\mathrm{n}=58 ; 5.3 \%)$, South America $(\mathrm{n}=45$; $4.1 \%)$, and South Africa $(\mathrm{n}=17 ; 1.6 \%)$. Almost three quarters of the patients were men and the median age was approximately 60 years. Overall, 998 (90.4\%) of the patients were white. Most patients had stage IV disease $(n=757$; $69.2 \%)$ or IIIB with malignant pleural effusion $(\mathrm{n}=239$; $21.9 \%)$. Most patients $(\mathrm{n}=984 ; 90.0 \%)$ had a performance status of 0 or 1 . The most common histology types were adenocarcinoma and squamous-cell carcinoma, seen in 504 $(46.1 \%)$ and 328 patients $(30.0 \%)$, respectively. The three treatment arms were well balanced (Table 1). The median follow-up duration was 15.9 months.

\section{Efficacy}

At each interim analysis, the Independent Data Monitoring Committee recommended that the trial continue. At the time of this analysis, 732 and 628 events were observed for survival and time to progression, respectively, with a minimum follow-up of 12 months for overall survival and 6 months for all other end points. There was no statistically significant difference in overall survival between each of the gefitinib arms and the placebo arm. The median survival times were 9.9 months for each of the gefitinib groups, and 10.9 months for the placebo group (GOLrank $P=.4560$; Fig 2). One-year survival rates were $43 \%$ and $41 \%$ for the $500 \mathrm{mg} / \mathrm{d}$ and $250 \mathrm{mg} / \mathrm{d}$ gefitinib groups, respectively, and $44 \%$ for the placebo group. Similarly, median time to progression was 5.5 and 5.8 months for the $500 \mathrm{mg} / \mathrm{d}$ and 250 $\mathrm{mg} / \mathrm{d}$ gefitinib groups, respectively, and 6.0 months in the placebo group, with no statistically significant difference

\begin{tabular}{|c|c|c|c|}
\hline & $\begin{array}{l}\text { Gefitinib } \\
500 \mathrm{mg} / \mathrm{d} \\
(\mathrm{n}=365)\end{array}$ & $\begin{array}{c}\text { Gefitinib } \\
250 \mathrm{mg} / \mathrm{d} \\
(\mathrm{n}=365)\end{array}$ & $\begin{array}{c}\text { Placebo } \\
(n=363)\end{array}$ \\
\hline \multicolumn{4}{|l|}{ Sex, \% } \\
\hline Female & 27.9 & 23.3 & 27.8 \\
\hline Male & 72.1 & 76.7 & 72.2 \\
\hline \multicolumn{4}{|l|}{ Age, years } \\
\hline Median & 61 & 59 & 61 \\
\hline Range & $31-85$ & $34-83$ & $33-81$ \\
\hline \multicolumn{4}{|l|}{ Disease stage, \%* } \\
\hline IIla & 3.0 & 1.6 & 1.9 \\
\hline $\mathrm{IIlb}$ & 29.9 & 25.8 & 28.4 \\
\hline Without pleural effusion & 5.5 & 6.3 & 6.6 \\
\hline With pleural effusion & 24.4 & 19.5 & 21.8 \\
\hline IV & 66.8 & 72.3 & 68.6 \\
\hline \multicolumn{4}{|l|}{ WHO performance status, \%* } \\
\hline 0 & 32.1 & 34.0 & 33.9 \\
\hline 1 & 58.1 & 56.4 & 55.6 \\
\hline 2 & 9.6 & 9.6 & 9.6 \\
\hline \multicolumn{4}{|l|}{ Weight loss in previous 6 months, \%* } \\
\hline$\leq 5 \%$ & 62.7 & 64.1 & 63.9 \\
\hline$>5 \%$ & 37.0 & 35.6 & 35.0 \\
\hline \multicolumn{4}{|l|}{ Disease measurability, \%* } \\
\hline Measurable & 94.8 & 94.8 & 93.4 \\
\hline Nonmeasurable & 4.9 & 4.9 & 5.8 \\
\hline \multicolumn{4}{|l|}{ Histology, \%* } \\
\hline Squamous & 28.8 & 32.1 & 29.2 \\
\hline Adenocarcinoma & 43.3 & 48.5 & 46.6 \\
\hline Squamous and adenocarcinoma & 2.7 & 1.4 & 1.4 \\
\hline Bronchoalveolar & 1.1 & 0.8 & 0.3 \\
\hline Undifferentiated & 11.5 & 9.3 & 11.8 \\
\hline Large cell & 11.5 & 7.7 & 8.8 \\
\hline \multicolumn{4}{|l|}{ Race, \% } \\
\hline White & 91.0 & 90.4 & 89.8 \\
\hline Black & 0.8 & 1.4 & 1.4 \\
\hline Asian & 1.9 & 1.6 & 0.8 \\
\hline Hispanic & 1.4 & 2.5 & 2.2 \\
\hline Oriental & 4.9 & 3.6 & 5.8 \\
\hline Other & 0.0 & 0.5 & 0.0 \\
\hline \multicolumn{4}{|l|}{ Metastatic disease, $\% \dagger$} \\
\hline Lung, other & 54.9 & 53.4 & 51.0 \\
\hline Bone & 30.3 & 34.8 & 37.8 \\
\hline Liver & 21.7 & 22.3 & 20.5 \\
\hline Adrenal tissue & 21.3 & 22.7 & 19.7 \\
\hline Lymph nodes & 10.2 & 10.2 & 14.1 \\
\hline Skin or soft tissue & 5.7 & 5.3 & 7.2 \\
\hline Brain & 5.3 & 4.5 & 2.8 \\
\hline Other & 7.8 & 4.9 & 4.8 \\
\hline
\end{tabular}

between treatment arms (GOLrank $P=.7633$; Fig 3). In the posthoc multivariate analysis, a performance status of 2 , weight loss, and bone and liver metastases were significant $(P<.05)$ predictors of worse survival outcome. In the posthoc univariate analysis examining known NSCLC prognostic factors and subgroups of sex, time on chemotherapy, and histology, no survival differences were seen 


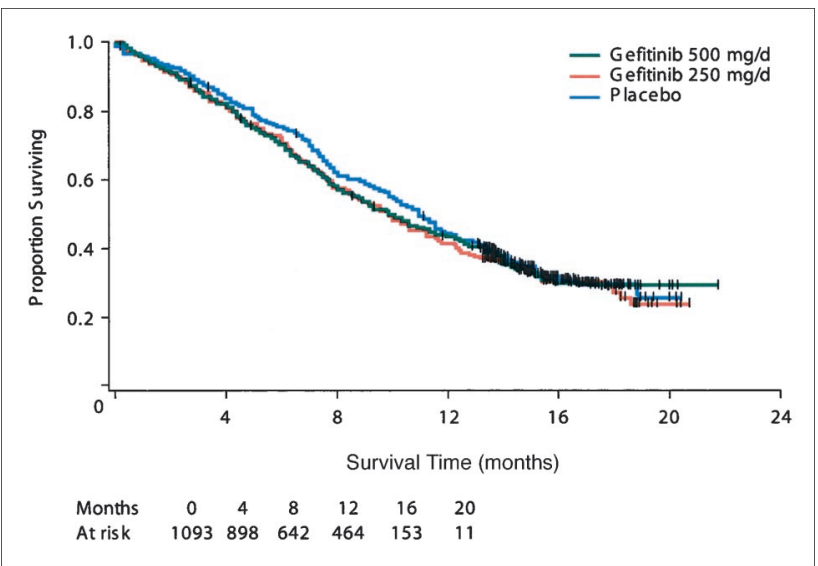

Fig 2. Kaplan-Meier estimates of overall survival in each treatment group. (global ordered log-rank $P=.4560$ ).

between treatments for any subgroups of patients [20]. Objective tumor response rates were $50.3 \%$ and $51.2 \%$ for the $500 \mathrm{mg} / \mathrm{d}$ and $250 \mathrm{mg} / \mathrm{d}$ gefitinib groups, respectively, and $47.2 \%$ in the placebo group ( $P=$ not significant). Very few complete responses were seen (Table 2).

\section{Duration of Therapy, Dose Intensity, and Dose Adherence}

The dose-intensity of both gemcitabine and cisplatin was similar in all three treatment groups (Table 3), demonstrating that chemotherapy dose intensity was not compromised by the addition of gefitinib. There was a high overall adherence to gefitinib; however, most gefitinib dose interruptions and reductions were seen in the gefitinib $500 \mathrm{mg} / \mathrm{d}$ arm (the number was similar in the gefitinib $250 \mathrm{mg} / \mathrm{d}$ and placebo arms) [Table 3]. Patients receiving gefitinib 250 $\mathrm{mg} / \mathrm{d}$ or placebo had a longer therapy duration than those receiving gefitinib $500 \mathrm{mg} / \mathrm{d}$.

\section{Safety and Tolerability}

Most adverse events occurred during the combination phase of the trial and many were consistent with the known

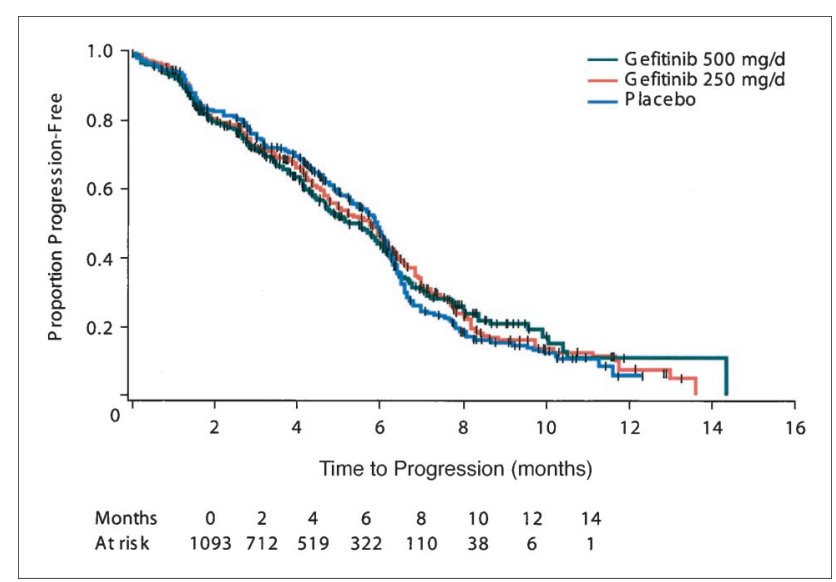

Fig 3. Kaplan-Meier estimates of time to progression in each treatment group. (global ordered log-rank $P=$.7633).
Table 2. Objective Tumor Responses in Each Treatment Group (population assessable for tumor response)

\begin{tabular}{lccc}
\hline & \multicolumn{3}{c}{ Objective Tumor Response (\%) } \\
\cline { 2 - 4 } & $\begin{array}{c}\text { Gefitinib } \\
500 \mathrm{mg} / \mathrm{d}\end{array}$ & $\begin{array}{c}\text { Gefitinib } \\
250 \mathrm{mg} / \mathrm{d}\end{array}$ & Placebo \\
& $(\mathrm{n}=330)$ & $(\mathrm{n}=336)$ & $(\mathrm{n}=324)$ \\
\hline Complete response & 2.1 & 3.3 & 0.9 \\
Partial response & 48.2 & 47.9 & 46.3 \\
$\begin{array}{l}\text { Response rate (complete plus } \\
\text { partial response) }\end{array}$ & 50.3 & 51.2 & 47.2 \\
\hline & & & \\
\hline
\end{tabular}

toxicities of the chemotherapy agents. Overall, the safety data from the monotherapy period of the trial support the gefitinib safety profile previously established in phase I and II trials. The most commonly occurring adverse events were gastrointestinal, skin-related, or hematologic in nature. Statistical analysis of prespecified adverse events during the chemotherapy phase revealed no difference between treatment arms except for diarrhea and skin events (diarrhea $P<.0001$ for $500 \mathrm{mg} / \mathrm{d} v 250 \mathrm{mg} / \mathrm{d}$ or placebo; $P=.0924$ for $250 \mathrm{mg} / \mathrm{d} v$ placebo; defined skin events $P<.0001$ for all comparisons [no adjustments were made to the $P$ values to take account of the multiple comparisons]), which are known to be associated with gefitinib treatment. A clear dose-response relationship was observed for these events. Interstitial lung disease (ILD)-type events were experienced by three, one, and three patients in the gefitinib $500 \mathrm{mg} / \mathrm{d}$, gefitinib $250 \mathrm{mg} / \mathrm{d}$, and placebo arms, respectively, giving an overall incidence of less than 1\%. The incidence of ILD-type events and other respiratory events that were possibly indicative of ILD is summarized in Table 4. No difference in reports of symptoms possibly related to, or indicative of, ILD (eg, dyspnea, increased cough, pneumonia) was seen between the groups.

The most frequently occurring adverse events considered by the investigators to be related to gefitinib/placebo treatment were rash, diarrhea, and acne, which were generally mild (grade 1 or 2; Table 5). No significant additive toxicity was evident in this placebo-controlled setting. Deaths and withdrawals owing to gefitinib/placebo-related toxicity were low and balanced between the three treatment arms. The proportion of patients withdrawn from treatment because of adverse events of any cause was higher (23.0\%) for patients in the $500 \mathrm{mg} / \mathrm{d}$ group, compared with $14.5 \%$ and $11.3 \%$ for $250 \mathrm{mg} / \mathrm{d}$ and placebo groups, respectively. The types of events leading to withdrawal were similar across the three groups: diarrhea, nausea, vomiting, and acne-like rash.

\section{DISCUSSION}

In this study, gefitinib showed no survival benefit over placebo when combined with gemcitabine and cisplatin in a large population of chemotherapy-naive patients with advanced NSCLC. Furthermore, gefitinib did not improve 


\begin{tabular}{|c|c|c|c|}
\hline & $\begin{array}{c}\text { Gefitinib } 500 \mathrm{mg} / \mathrm{d} \\
\quad(n=358)\end{array}$ & $\begin{array}{c}\text { Gefitinib } 250 \mathrm{mg} / \mathrm{d} \\
(n=362)\end{array}$ & $\begin{array}{l}\text { Placebo } \\
(n=355)\end{array}$ \\
\hline \multicolumn{4}{|l|}{ Gefitinib } \\
\hline Median duration of gefitinib/placebo therapy, days & 97 & 150 & 159 \\
\hline Dose interruption, \%* & 45.8 & 26.8 & 17.2 \\
\hline Dose reduction, \%* & 23.2 & 6.4 & 2.8 \\
\hline Median dose adherence, \% & 91.8 & 97.7 & 99.5 \\
\hline \multicolumn{4}{|l|}{ Chemotherapy } \\
\hline Median No. of chemotherapy cycles & 4 & 6 & 6 \\
\hline Gemcitabine median dose-intensity, \% & 84.2 & 84.6 & 85.9 \\
\hline Cisplatin median dose-intensity, $\%$ & 92.0 & 91.9 & 92.4 \\
\hline
\end{tabular}

time to progression or objective tumor response over chemotherapy alone. Similar results were seen in the twin study INTACT 2, in which gefitinib was evaluated in combination with paclitaxel and carboplatin [15]. These results are disappointing and surprising because of the significant antitumor activity of gefitinib when given alone to pretreated patients with advanced NSCLC $[9,11]$ and because additive or synergistic activities of gefitinib and several chemotherapeutic drugs have been seen in preclinical models [12]. However, it should be noted that phase II data were not available when these studies were initiated.

The results of two similar trials investigating the use of another EGFR-TKI, erlotinib, in combination with gemcitabine and cisplatin or paclitaxel and carboplatin, have recently been reported. As in our study, the addition of an EGFR-TKI to first-line chemotherapy in patients with advanced NSCLC did not result in any improvement in overall survival over chemotherapy alone.

No significant adverse events were seen that were not predictable from the safety profiles of gefitinib monotherapy and gemcitabine and cisplatin. Furthermore, the safety profile was similar for all treatment arms, with the exception of dose-related additive diarrhea and skin toxicity. As in the phase II gefitinib monotherapy trials, more dose interruptions and reductions of gefitinib were seen in the $500 \mathrm{mg} / \mathrm{d}$ arm. Furthermore, although the chemotherapy dose-intensity was similar across the treatment arms,

\begin{tabular}{|c|c|c|c|}
\hline & $\begin{array}{l}\text { Gefitinib } \\
500 \mathrm{mg} / \mathrm{d} \\
(\mathrm{n}=358)\end{array}$ & $\begin{array}{l}\text { Gefitinib } \\
250 \mathrm{mg} / \mathrm{d} \\
(\mathrm{n}=362)\end{array}$ & $\begin{array}{c}\text { Placebo } \\
(\mathrm{n}=355)\end{array}$ \\
\hline Dyspnea, \% & 17.9 & 17.7 & 23.1 \\
\hline Cough, \% & 15.4 & 17.7 & 18.3 \\
\hline Pneumonia, \% & 3.9 & 5.5 & 4.8 \\
\hline ILD event, $\mathrm{n}$ & 3 & 1 & 3 \\
\hline
\end{tabular}

Abbreviation: ILD, interstitial lung disease. patients on the $500 \mathrm{mg} / \mathrm{d}$ arm received a lower median number of chemotherapy cycles. This may have been due to a higher degree of antagonism occurring in this arm, leading to earlier disease progression. These results confirm, in a placebo-controlled setting, that gefitinib has a favorable safety profile and that $250 \mathrm{mg} / \mathrm{d}$ is better tolerated than 500 $\mathrm{mg} / \mathrm{d}$. Recently published data suggest that gefitinib might be associated with interstitial pneumonia [21]; however, in our study, the overall incidence of ILD was less than $1 \%$, and no imbalance was identified across the three treatment arms in terms of pneumonitis/ILD-type events. One patient receiving gefitinib $250 \mathrm{mg} / \mathrm{d}$ and three patients each in the gefitinib $500 \mathrm{mg} / \mathrm{d}$ and placebo groups were reported to have experienced an ILD-type event. Furthermore, there was no difference between arms in reports of symptoms possibly related to, or indicative of, ILD, such as dyspnea, cough, or pneumonia. Interestingly, the frequency of ILD-type events in patients receiving gefitinib seems to be higher in Japanese patients $(1.9 \%)$ than in the rest of the world $(0.34 \%$; data on file, AstraZeneca, Wilmington, DE). As yet, the reason for this is unknown, although it may be related to population or environmental differences, or differences in clinical practice.

The reasons for the disappointing efficacy results are still unclear. It is possible that each of the agents is working against a susceptible subpopulation of tumor cells so that the effect is redundant rather than additive, or that one agent results in the loss of an intermediary molecule that is essential to the function of the other agent, resulting in an antagonistic effect.

Patients included in this study and all other studies with gefitinib were not selected on the basis of presence of the target EGFR. Samples from approximately one third of the patients accrued in the study are being immunohistochemically assessed for expression of the receptor. Of course it is conceivable that if only a small number of patients are sensitive to gefitinib, the diluting effect of the lack of selection might make it impossible to discern small differences. A sharper definition of such susceptible subgroups of patients will certainly help in further develop- 


\begin{tabular}{|c|c|c|c|c|c|c|}
\hline & \multicolumn{6}{|c|}{ Adverse Event (\%) } \\
\hline & \multicolumn{2}{|c|}{ Gefitinib 500 mg/d (n = 358) } & \multicolumn{2}{|c|}{ Gefitinib $250 \mathrm{mg} / \mathrm{d}(\mathrm{n}=362)$} & \multicolumn{2}{|c|}{ Placebo $(n=355)$} \\
\hline & All & Grade $3 / 4$ & All & Grade $3 / 4$ & All & Grade $3 / 4$ \\
\hline Rash & 56.7 & 12.6 & 44.5 & 3.6 & 21.4 & 1.1 \\
\hline Diarrhea & 50.8 & 12.0 & 28.7 & 3.6 & 15.5 & 2.3 \\
\hline Acne & 28.2 & 5.9 & 18.2 & 1.4 & 5.1 & 0.3 \\
\hline Nausea & 19.0 & 4.5 & 17.1 & 2.5 & 17.5 & 2.0 \\
\hline Vomiting & 17.0 & 4.7 & 13.8 & 2.8 & 12.4 & 2.3 \\
\hline Pruritus & 12.6 & 2.0 & 7.5 & 0 & 7.0 & 0 \\
\hline Asthenia & 10.9 & 2.2 & 9.7 & 1.9 & 10.1 & 0.8 \\
\hline Dry skin & 9.5 & 0 & 7.2 & 0 & 3.1 & 0 \\
\hline Anorexia & 7.0 & 1.7 & 5.2 & 0.6 & 4.8 & 0.3 \\
\hline Thrombocytopenia & 7.0 & 4.2 & 7.7 & 5.8 & 7.9 & 5.6 \\
\hline Anemia & 5.0 & 2.5 & 3.9 & 1.9 & 6.2 & 1.7 \\
\hline Neutropenia & 5.0 & 5.0 & 5.0 & 5.8 & 7.0 & 4.8 \\
\hline Leukopenia & 3.9 & 2.0 & 2.0 & 3.3 & 4.5 & 2.5 \\
\hline Conjunctivitis & 5.3 & 0.3 & 0.3 & 2.5 & 2.8 & 0 \\
\hline
\end{tabular}

ment of this type of agent, for which the expression of the target is unlikely to accurately predict the activity of the therapy. In fact, the level of expression of EGFR was not predictive of the sensitivity to gefitinib in a number of in vitro systems [22], and immunohistochemical analysis of samples from the two phase II trials of gefitinib monotherapy in patients with pretreated advanced NSCLC did not provide any evidence of a correlation between EGFR expression levels and either response or symptom improvement. Indeed, substantial numbers of EGFR-negative patients benefited from gefitinib, whereas some patients with intense EGFR staining did not show any response [23].

It seems that inhibition of EGFR autophosphorylation rather than expression of the receptor might impact on the activity of this agent. Furthermore, the assessment of pathways downstream from the activation cascade of EGFR (PI3K/Akt and Ras/Erk) might give more insight into the possibility of inactivating the receptor cascade.

Because no additive effect was observed by administering gefitinib continuously in combination with chemotherapy, possible alternatives could be the administration of gefitinib in the interval between chemotherapy cycles or as maintenance treatment after chemotherapy. This could also potentially prevent the problem of drug interference or antagonism.

In conclusion, INTACT 1 did not show superior efficacy of gefitinib added to gemcitabine and cisplatin in patients with advanced NSCLC. Previous studies have shown that gefitinib is an active agent for a number of patients with advanced NSCLC, so further work is needed to identify subsets of patients who may benefit more from this therapy. Additional preclinical studies may shed light on the lack of additive or synergistic activity in unselected human tumors.

\section{Authors' Disclosures of Potential Conflicts of Interest}

The following authors or their immediate family members have indicated a financial interest. No conflict exists for drugs or devices used in a study if they are not being evaluated as part of the investigation. Acted as a consultant within the last 2 years: Giuseppe Giaccone, AstraZeneca; Roy S. Herbst, AstraZeneca; Christian Manegold, AstraZeneca; Giorgio Scagliotti, AstraZeneca; Joan Schiller, AstraZeneca; Ronald Natale, AstraZeneca; Vincent Miller, AstraZeneca; Ulrich Gatzemeier, AstraZeneca; David H. Johnson, AstraZeneca. Received more than \$2,000 per year from a company for either of the last 2 years: Ronald Natale, AstraZeneca; Vincent Miller, AstraZeneca.

\section{Appendix}

The appendix is included in the full-text version of this article, available on-line at www.jco.org. It is not included in the PDF (via Adobe ${ }^{\circledR}$ Acrobat Reader ${ }^{\circledR}$ ) version.

\section{REFERENCES}

1. Non-small Cell Lung Cancer Collaborative Group: Chemotherapy in non-small cell lung cancer: A meta-analysis using updated data on individual patients from 52 randomised clinical trials. BMJ 311:899-909, 1995
2. Schiller $\mathrm{JH}$, Harrington $\mathrm{D}$, Belani $\mathrm{CP}$, et al: Comparison of four chemotherapy regimens for advanced non-small-cell lung cancer. $N$ Engl J Med 346:92-98, 2002

3. Cardenal F, Lopez-Cabrerizo MP, Anton A et al: Randomized phase III study of gemcitabine-cisplatin versus etoposide-cisplatin in the treatment of locally advanced or metastatic non- small-cell lung cancer. J Clin Oncol 17:12-18, 1999

4. Sandler AB, Nemunaitis J, Denham C, et al: Phase III trial of gemcitabine plus cisplatin versus cisplatin alone in patients with locally advanced or metastatic nonsmall-cell lung cancer. J Clin Oncol 18:122130, 2000 
5. Baselga J: New technologies in epidermal growth factor receptor-targeted cancer therapy. Signal 1:12-21, 2000

6. Wells $A$ : The epidermal growth factor receptor (EGFR): A new target in cancer therapy Signal 1:4-11, 2000

7. Woodburn JR: The epidermal growth factor receptor and its inhibition in cancer therapy. Pharmacol Ther 82:241-250, 1999

8. Douillard J-Y, Giaccone G, Horai $T$, et al: Improvement in disease-related symptoms and quality of life in patients with advanced nonsmall-cell lung cancer (NSCLC) treated with ZD1839 ('Iressa') (IDEAL 1). Proc Am Soc Clin Oncol 21:298a, 2002 (abstr 1195)

9. Kris MG, Natale RB, Herbst RS, et al: Efficacy of gefitinib, an inhibitor of the epidermal growth factor receptor tyrosine kinase, in symptomatic patients with non-small cell lung cancer: A randomized trial. JAMA 290:2149-2158, 2003

10. Natale RB, Skarin A, Maddox A-M, et al: Improvement in symptoms and quality of life for advanced non-small-cell lung cancer patients receiving ZD1839 ('Iressa') in IDEAL 2. Proc Am Soc Clin Oncol 21:292a, 2002 (abstr 1167)

11. Fukuoka M, Yano S, Giaccone $G$, et al: Multi-institutional randomized phase II trial of gefitinib for previously treated patients with advanced non-small-cell lung cancer. J Clin Oncol 21:2237-2246, 2003
12. Ciardiello F, Caputo $R$, Bianco $R$, et al: Antitumor effect and potentiation of cytotoxic drugs activity in human cancer cells by ZD-1839 (Iressa), an epidermal growth factor receptorselective tyrosine kinase inhibitor. Clin Cancer Res 6:2053-2063, 2000

13. Sirotnak FM, Zakowski MF, Miller VA, et al: Efficacy of cytotoxic agents against human tumor xenografts is markedly enhanced by coadministration of ZD1839 (Iressa), an inhibitor of EGFR tyrosine kinase. Clin Cancer Res 6:4885-4892, 2000

14. Gonzalez-Larriba JL, Giaccone G, van Oosterom A, et al: ZD1839 ('Iressa') in combination with gemcitabine and cisplatin in chemonaive patients with advanced solid tumours: Final results of a phase I trial. Proc Am Soc Clin Oncol 21:95a, 2002 (abstr 376)

15. Herbst RS, Giaccone G, Schiller JH, et al: Gefitinib in combination with paclitaxel and carboplatin in chemotherapy-naive patients with advanced non-small-cell lung cancer: Results from a phase III clinical trial-INTACT 2. J Clin Oncol 22:785-794, 2004

16. Pocock SJ, Simon R: Sequential treatment assignment with balancing for prognostic factors in the controlled clinical trial. Biometrics 31:103115, 1975

17. World Medical Association Declaration of Helsinki: Recommendations guiding physicians in biomedical research involving human subjects. JAMA 277:925-926, 1997

18. Therasse $P$, Arbuck SG, Eisenhauer EA, et al: New guidelines to evaluate the response to treatment in solid tumors. J Natl Cancer Inst 92:205-216, 2000

19. Rom DM, Costello RJ, Connell LT: On closed test procedures for dose-response analysis. Stat Med 13:1583-1596, 1994

20. Herbst R, Giaccone G, Schiller J, et al: Subset analyses of INTACT results for gefitinib ('Iressa', ZD1839) when combined with platinum-based chemotherapy for advanced nonsmall-cell lung cancer. Proc Am Soc Clin Onco 22:627, 2003 (abstr 2523)

21. Inoue $A$, Saijo $Y$, Maemondo $M$, et al: Severe acute interstitial pneumonia and gefitinib. Lancet 361:137-139, 2003

22. Arteaga CL: Epidermal growth factor receptor dependence in human tumors: More than just expression? Oncologist 7:31-39, 2002 (suppl 4)

23. Bailey LR, Kris $M$, Wolf $M$, et al: Tumor EGFR membrane staining is not clinically relevant for predicting response in patients receiving gefitinib ('Iressa', ZD1839) monotherapy for pretreated advanced non-small-cell lung cancer IDEAL 1 and 2. Proc Am Assoc Cancer Res 44:1362, 2003 (abstr LB-170) 